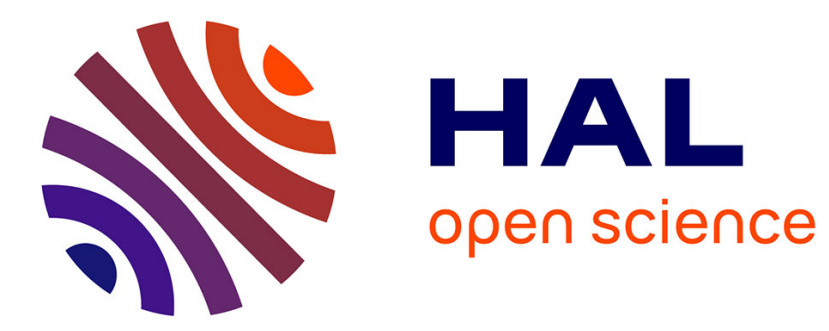

\title{
Control of separated flows with the ionic wind generated by a DC corona discharge
}

Pierre Magnier, Dunpin Hong, Annie Leroy-Chesneau, Jean-Marc Bauchire, Jacques Hureau

\section{To cite this version:}

Pierre Magnier, Dunpin Hong, Annie Leroy-Chesneau, Jean-Marc Bauchire, Jacques Hureau. Control of separated flows with the ionic wind generated by a DC corona discharge. Experiments in Fluids, 2007, 42, pp. 815-825. 10.1007/s00348-007-0297-z . hal-00264825

\section{HAL Id: hal-00264825}

\section{https://hal.science/hal-00264825}

Submitted on 18 Mar 2008

HAL is a multi-disciplinary open access archive for the deposit and dissemination of scientific research documents, whether they are published or not. The documents may come from teaching and research institutions in France or abroad, or from public or private research centers.
L'archive ouverte pluridisciplinaire HAL, est destinée au dépôt et à la diffusion de documents scientifiques de niveau recherche, publiés ou non, émanant des établissements d'enseignement et de recherche français ou étrangers, des laboratoires publics ou privés. 
Pierre Magnier · Dunpin Hong · Annie

Leroy-Chesneau · Jean-Marc Bauchire · Jacques

Hureau

\title{
Control of separated flows with the ionic wind generated
}

\section{by a DC corona discharge}

Received: date / Revised version: date

\begin{abstract}
This paper describes the investigation of a DC surface corona discharge established on a rounded edge of a dielectric material. The ionic wind induced by the discharge was measured with the Particle Image Velocimetry system. A physical induced flow model is proposed to interpret the shape of the velocity field. Experiments on a flat plate and a NACA 0015 were performed in a subsonic wind tunnel. They showed that the flow induced by this discharge acted close to the wall and modified the fully detached flow on the airfoil up to $R e=267000$ and $17.5^{\circ}$ by a combined effect of the discharge and a Reynolds effect.
\end{abstract}

Keywords Flow control · Corona Discharge · Electrohydrodynamics · Ionic Wind · Plasma Actuator

\section{Introduction}

A high voltage discharge created between two electrodes creates the ionisation of the neutral gas. Ions and electrons are generated by collisions, under the action of the Coulomb force. The ion migration induces the movement of neutral molecules by exchanging momentum. This flow induced by the charged particles is generally called "ionic wind" (Robinson (1961)). It had been studied in many applications, for

P Magnier, A Leroy-Chesneau, J Hureau

Laboratoire de Mécanique et d'Énergétique, 8 rue Léonard de Vinci 45072 Orléans Cedex 02, France

Tel.: +0033-(0)2 38494351

E-mail: pierre.magnier@univ-orleans.fr

D Hong, JM Bauchire

GREMI, UMR 6606, CNRS / Université d'Orléans, 14 rue d'Issoudun BP 6744, 45072 Orléans Cedex 02, France Tel.: +0033-(0)2 38494527

E-mail: dunpin.hong@univ-orleans.fr 
example in electrostatic precipitators used to remove smoke (Leonard et al. (1983), Soldati and Banerjee (1998)). The efficiency of an electrostatic precipitator (i.e. the ability to collect particles) depends on the electrode geometry (Jedrusik et al. (2001), Kuroda et al. (2003)), so depends on the shape of the electric field created between electrodes, and consequently depends on the shape of the ionic wind induced by the electric discharge. The turbulence intensity of the main flow is increased by a high voltage discharge in electrostatic precipitators (Davidson and Shaughnessy (1986)), due to the presence of rotating turbulent structures caused by interactions of the main flow with the ionic wind (Yamamoto and Velkoff (1981)). Since this induced flow enables a better mixing of gas, it has also been studied for its application to heat transfer enhancement (Marco and Velkoff (1964), Kalman and Sher (2001)).

The principle to control a flow by gas injection or energy add is used since decades. Therefore the use of the ionic wind added to a flow has been studied in aerodynamics for about 10 years. The main objectives are the modification of the position of the laminar-turbulent transition, the reduction of the wake and the drag of an obstacle. Flow control perspectives are important for aeronautics: for example, a $5 \%$ decrease in the drag of an aircraft results in a $40 \%$ increase in payload (Anders et al. (2004)). An electrohydrodynamic (EHD) actuator directly converts electrical energy into mechanical energy. The advantages of this kind of control is that this EHD actuator does not require moving mechanical parts and has a very short response time (because of complete electric control). The ability to control a flow with electric discharges has been shown by many experiments, such as the use of a DC corona discharge for modifying the wake of a cylinder for low Reynolds numbers. Electrodes can be placed on the cylinder surface (Artana et al. (2001) for Reynolds numbers between 21250 and 42 500) or away from the cylinder (Hyun and Chun (2003) for Reynolds numbers up to 4 000). The position of the flow separation line is therefore delayed, and the wake is reduced. The ionic wind induced by the EHD actuator is added to the boundary layer, in the vicinity of the surface. So electric discharges were used for affecting the laminarturbulent transition location on a flat plate. If the electric discharge is applied such as the ionic wind is in the same direction as the main flow, the transition can be delayed (Velkoff and Ketcham (1968)), or if the ionic wind is in the opposite direction, the transition can be moved forward (Roth et al. (1998)). These modifications of the boundary layer imply changes of the drag force applied to the plate. AC and DC electric discharges enable a significant reduction of the drag force (Roth et al. (1998), Moreau et al. (2006)). Shcherbakov et al. (2000) measured a drag decrease of $5.3 \%$ on a wing-like profile plate with an 
AC corona discharge. El-Khabiry and Colver (1997) have also shown numerically an acceleration of the boundary layer and a drag reduction by application of a corona discharge on a flat plate.

These effects demonstrate the usefulness that could have an EHD actuator in aeronautics domain. The flow on a wing profile can be significantly modified, for avoiding detachment and for reducing drag force. EHD actuator placed at the leading edge of a wing profile has similar effects as leading edge slats, and EHD actuator placed at the trailing edge is comparable to flaps (Corke et al. (2006)). Indeed, these moving parts and the electric discharges can increase the lift force while delaying the stall. Thus the use of pulsed discharges lead them to delay airfoil separation up to $460 \times 10^{3}$ for Post and Corke (2003), and to modify airfoil characteristic curves (drift and drag coefficients) and to increase up to $+300 \%$ the lift-to-drag ratio for Reynolds numbers up to $307 \times 10^{3}$ (Corke et al. (2004)). With an AC dielectric barrier discharge, Roth et al. $(2000,2004)$ re-attached a separated flow on a NACA 0015 wing profile with the One Atmosphere Uniform Glow Discharge Plasma for inlet velocity up to $7.6 \mathrm{~m} / \mathrm{s}$ and angles of attack up to $12^{\circ}$, and Opaits et al. (2005) delayed the stall for inlet velocity up to $75 \mathrm{~m} / \mathrm{s}$ (with an $9 \mathrm{~cm}$-cord NACA 0015). AC discharges can also be used for unsteady control in order to perform an active control by adjusting the applied signal frequency (Sosa et al. (2004), Corke et al. (2006)).

DC corona surface discharges, such as presented here, were studied in many experiments and important effects were observed. Léger et al. (2001) and Artana et al. (2002) used this electric discharge for reattaching the flow and reducing the wake on a flate plate, for Reynolds number up to 68600 and for angles of attack up to $30^{\circ}$. Sosa and Artana (2006) placed this discharge at the trailing edge of a NACA 0015 airfoil for low Reynolds numbers (up to 50 000). Moreau et al. (2006) measured modifications on the boundary layer velocity profiles on a flat plate (null angle of attack, flow fully attached) for Reynolds numbers up to 375 000. Another application of this discharge is the separation of a naturally attached flow (Labergue et al. (2005) on an inclined wall).

The work presented here is the study of the aerodynamic characteristics of a continuous surface corona discharge. Electrodes were placed at the leading edge in order to modify the boundary layer in the area of flow separation at high angles of attack. The goal of our work is to measure the ability of a DC corona discharge to modify an airflow and above all to understand how it works. We focused on two aspects of the corona discharge. First we measured the ionic wind induced by the electric discharge on a flat plate, without external airflow. We used a pressure sensing probe made of glass and velocity fields were visualised with a Particle Image Velocimetry (PIV) system. Then this flat plate and a NACA 0015 wing 
profile were placed in a subsonic wind tunnel in order to study the effects of the discharge on the airflow. During these experiments on the airfoil, we used angles of attack between $12.5^{\circ}$ and $17.5^{\circ}$ and Reynolds numbers between 67000 and 333000 .

\section{Experimental setup}

\subsection{Plasma actuator on obstacles}

The plasma actuator investigated consists of a DC surface corona discharge generated between two flat electrodes, such as Sosa et al. (2004). They are mounted on both sides of the circular leading edge of a flat plate made of PVC (polyvinyl chloride), as shown in figure 1a. The flat plate is $200 \mathrm{~mm}$ long and $250 \mathrm{~mm}$ wide. The leading edge is a semi-circle with a radius $7.5 \mathrm{~mm}$. The electrodes are $170 \mathrm{~mm}$ long and $25 \mathrm{~mm}$ wide thin copper layers (35 $\mu \mathrm{m}$ thick), the cathode is placed $37 \mathrm{~mm}$ downstream the leading edge and the anode $8 \mathrm{~mm}$.

The same electrode configuration was also used on a NACA 0015 wing profile (figure 1b), also made of PVC (the same material as the flat plate was used in order to avoid an additional parameter). The airfoil dimensions were a cord of $200 \mathrm{~mm}$, a spanwise dimension of $300 \mathrm{~mm}$ and a maximum thickness of $30 \mathrm{~mm}$.

In order to obtain a DC corona discharge, the anode is connected, through a resistance of $15 \mathrm{M} \Omega$, to a positive high voltage power supply SPELLMAN SL300 $(0-60 \mathrm{kV}, 5 \mathrm{~mA})$. The resistance is used to avoid the transition of the discharge to an arc regime. The cathode is connected to the ground. Therefore the movement of positive ions follows the leading edge geometry, going from the anode to the cathode.

A stable and efficient discharge was obtained with a positive DC High Voltage equal to $+44 \mathrm{kV}$ applied to the anode. The mean discharge current measured is $0.21 \mathrm{~mA}$ (i.e. the current by electrode length is $1.2 \mathrm{~mA} / \mathrm{m}$ ), thus the electric power is about $9 \mathrm{~W}$. In figure 2, the DC surface corona discharge is established with the aspect of a homogeneous light in the interelectrode space along the span. This photo was obtained, when darkening the room, with an intensified charge couple device (ICCD) camera, during a $1 \mathrm{~s}$ exposure time. 


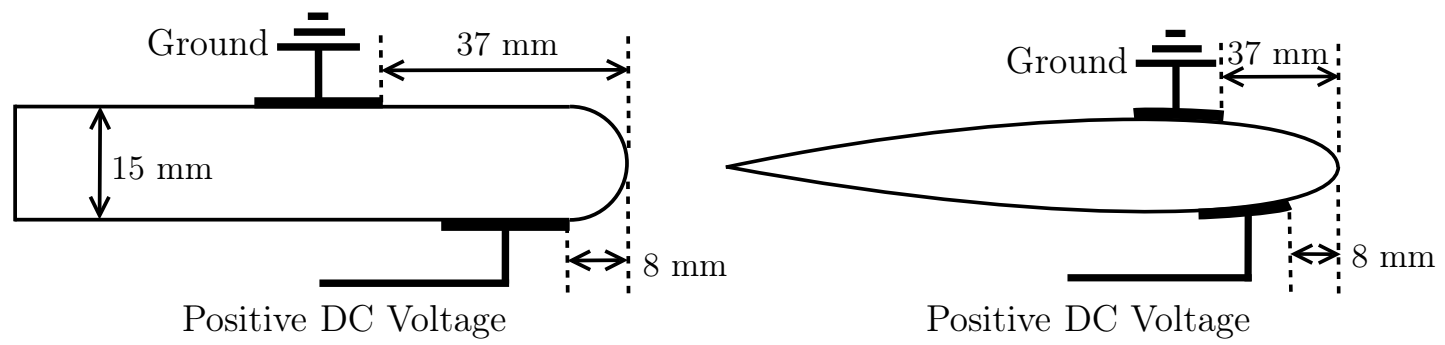

Fig. 1 Schematic side view of a DC surface corona discharge actuator (a) on a flat plate and (b) on a NACA 0015 wing profile

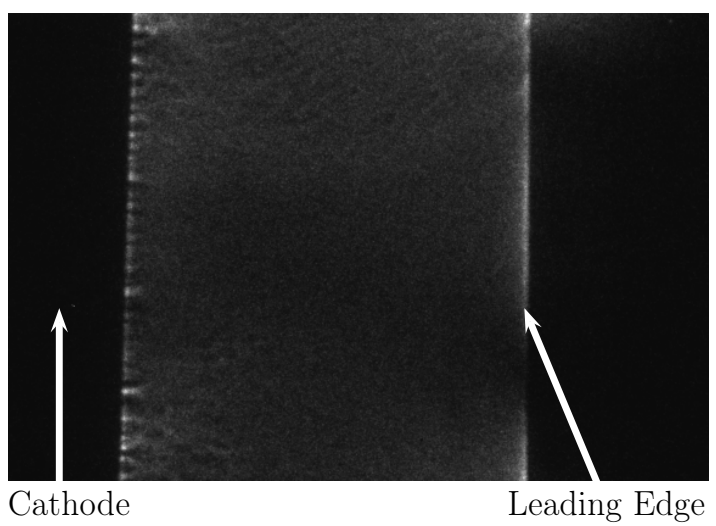

Fig. 2 Above view of a DC surface corona discharge generated on the flat plate

\subsection{Experimental conditions}

In order to perform experiments without external airflow, the flat plate with electrodes was placed inside a closed box, as shown in figure 3. Thus parasitic air movements (which would disturb measurements) were avoided and investigators were protected from the ozone produced by the plasma. The box walls were made of transparent Plexiglas $囚$, to enable the use of the Particle Image Velocimetry (PIV) system. Smoke for the PIV system was introduced into the box and was left to stand for a few minutes before experiments. Velocity fields were performed with the PIV system then and indicated that mean velocity values were less than $0.04 \mathrm{~m} / \mathrm{s}$ : thus we consider that the natural movement of smoke, without dicahrge, is negligible. Ozone and smoke were evacuated by the ventilation system once measurements were finished.

Experiments with airflow were performed in a subsonic open-circuit wind tunnel with a square test section of $50 \mathrm{~cm} \times 50 \mathrm{~cm}, 2 \mathrm{~m}$ long (figure 4). A $30 \mathrm{~kW}$ electric fan generates a maximum velocity of $50 \mathrm{~m} / \mathrm{s}$ in the test section. The mean turbulence ratio, measured by a hot wire in this section without an obstacle, is $0.4 \%$. Two flat plates $(100 \mathrm{~cm} \times 50 \mathrm{~cm})$ were installed to limit three-dimensional effects. The flow is two dimensional over more than $85 \%$ of the wind tunnel height and width. The obstacle was installed between two disks (40 $\mathrm{cm}$ in diameter) which rotate to place the obstacle at the desired 


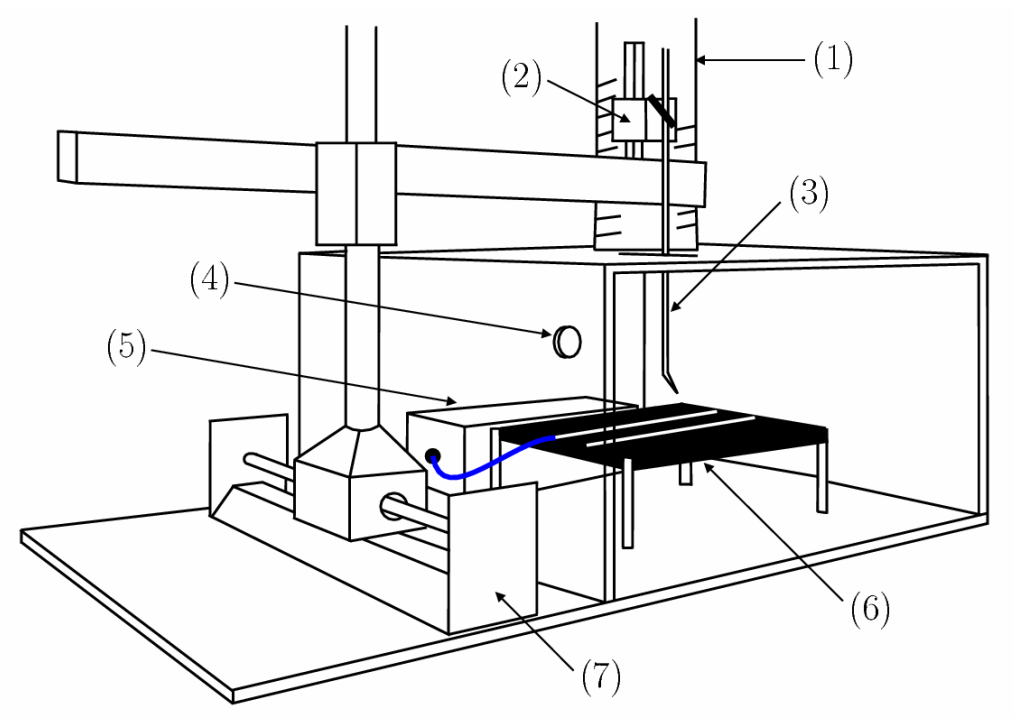

Fig. 3 Schematic of the experimental closed box with (1) ventilation system, (2) vertical displacement system of the pressure sensing probe, (3) pressure sensing probe, (4) air intake, (5) resistance box, (6) flat plate with electrodes, (7) horizontal deplacement system of the pressure sensing probe

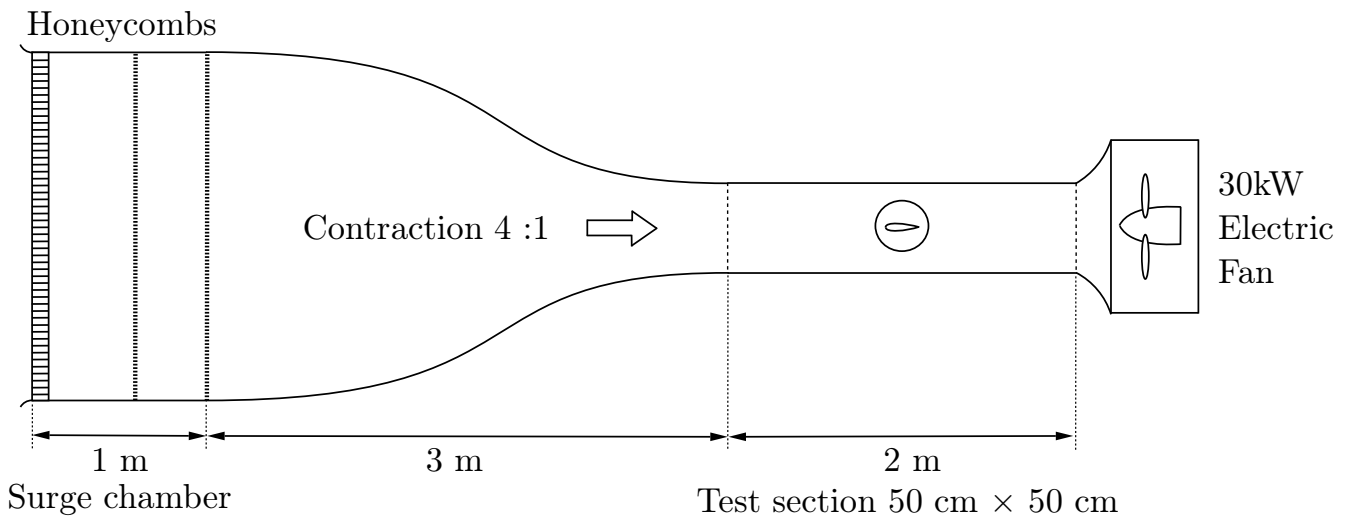

Fig. 4 Schematic side view of the subsonic wind tunnel

incidence. They are made of transparent Plexiglas@, for direct visualizations and video acquisitions. The fixations on both ends of the airfoil were made of electrically insulating material (Nylonß).

\subsection{Flow measurement}

\subsubsection{Pressure sensing probe}

Classical Pitot tubes are made of conductive materials whose presence close to the discharge must be avoided because of high voltage. Velocity measurements were therefore performed with a pressure sensing probe made of glass (Leger (2003), Moreau et al. (2006)), which allowed measurements to be made in the interelectrode space. The diameter of the inlet openning is $0.8 \mathrm{~mm}$. 


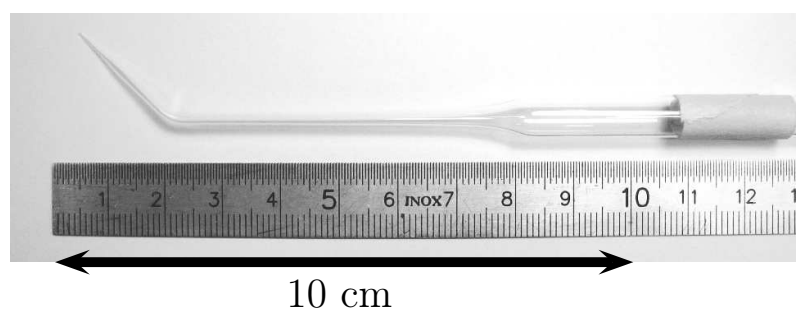

Fig. 5 Pressure sensing probe made of glass

They were calibrated with a calibration wind tunnel for hot wire probes (DANTEC StreamLine $90 \mathrm{H} 02$ Flow Unit) and compared with a classical metallic Pitot tube. The error made in pressure measurements is under $0.5 \%$ for a probe rotation of $\pm 7.5^{\circ}$.

The pressure sensing probe was connected to a differential low pressure transducer Druck ${ }^{\mathrm{TM}} \mathrm{LPM}$ 9481 from 0 to $20 \mathrm{~Pa}$, with output voltage 0 to $5 \mathrm{~V}$. The transducer measurement accuracy is $0.1 \%$ of the full range (i.e. $\pm 0.02 \mathrm{~Pa}$ ). Pressure measurements were acquired on a $\mathrm{PC}$ with a 16 -bit acquisition card. The resolution of the output voltage measured is $8 \times 10^{-5} \mathrm{~V}$ (i.e. $\pm 0.008 \mathrm{~Pa}$ ). Pressure measurements in each position were obtained over a $2 \mathrm{~s}$ interval at a $2-\mathrm{kHz}$ sampling rate.

\subsubsection{Particle Image Velocimetry system}

Measurements were performed using the PIV system, generating the two-dimensional components of the velocity around the obstacle. The laser sheet is generated by a double-oscillator system. During experiments we used the second harmonic $(\lambda=532 \mathrm{~nm})$ of an Nd:Yag Laser (Spectra Physics 400) emitting two pulses of $200 \mathrm{~mJ}$ each (with a time delay of $10 \mu \mathrm{s}$ ), at a repetition rate of $10 \mathrm{~Hz}$. The laser sheet is developed with the usual laser sheet optics, with mirrors and spherical and cylindrical lenses with negative and positive focal lengths (figure 6).

The images were obtained using a CCD camera with $1008 \times 1016$ pixels (camera CCD PIVCAM) placed perpendicularly to the laser sheet and in the direction of a section of the two-dimensional obstacle. The laser pulses are synchronized with the image acquisition by a TSI synchronizer system driven by InSight-NT ${ }^{\mathrm{TM}}$ software.

The PIV recordings are divided into small interrogation areas corresponding to $8 \times 8$ pixels. In the data post-processing, the interrogation areas overlap by $75 \%$, which corresponds to defining $122 \times 124$ vectors on the visualized area. The local displacement vector is determined for each interrogation area by statistical methods (auto-correlation). The projection of the local flow velocity vector onto the laser sheet plane is calculated by InSight ${ }^{\mathrm{TM}}$, using the time delay between the two illuminations $(\Delta t)$ and the 


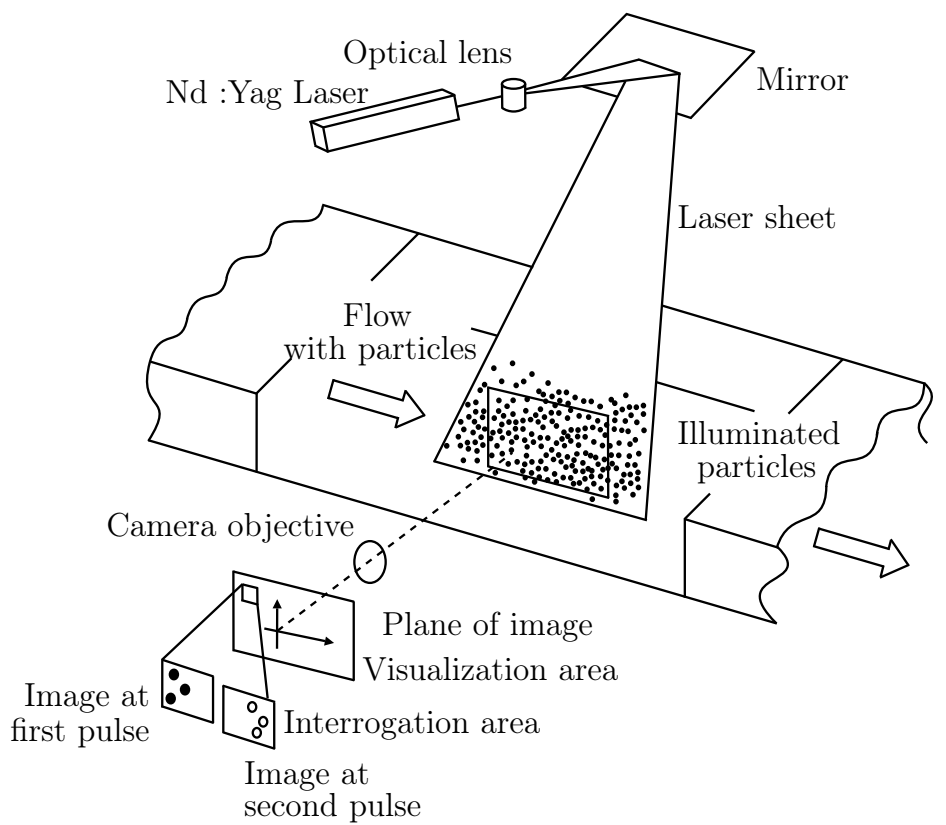

Fig. 6 Experimental setup of the Particle Image Velocimetry system

magnification at imaging.

The flow is seeded with tracer particles. After some experiments with smoke produced by an oil generator (with the oil Universal-Effects ${ }^{\mathrm{TM}}$ ), we observed modifications of the corona discharge with this smoke (higher current discharge, different discharge appearance) compared to without smoke. The electrostatic charge tendency of these smoke oil particles was probably non-negligible, whereas the use of smoke produced by incense sticks did not seem modifying the discharge (same electrical characteristics with and without this smoke). Consequently all the PIV measurements were performed with smoke generated by incense sticks.

\section{The ionic wind without airflow}

First, experiments were performed with the flat plate placed in the closed box without external airflow. Ionic wind induced by corona discharge were measured with two different means, and the electric discharge and ionic wind properties were studied.

3.1 Ionic wind velocity measurements

Without external flow, the only flow is that generated by the electric discharge. At different positions on the flat plate $(30 \mathrm{~mm}, 40 \mathrm{~mm}$ and $50 \mathrm{~mm}$ downstream the leading edge), velocity profiles of the ionic wind 

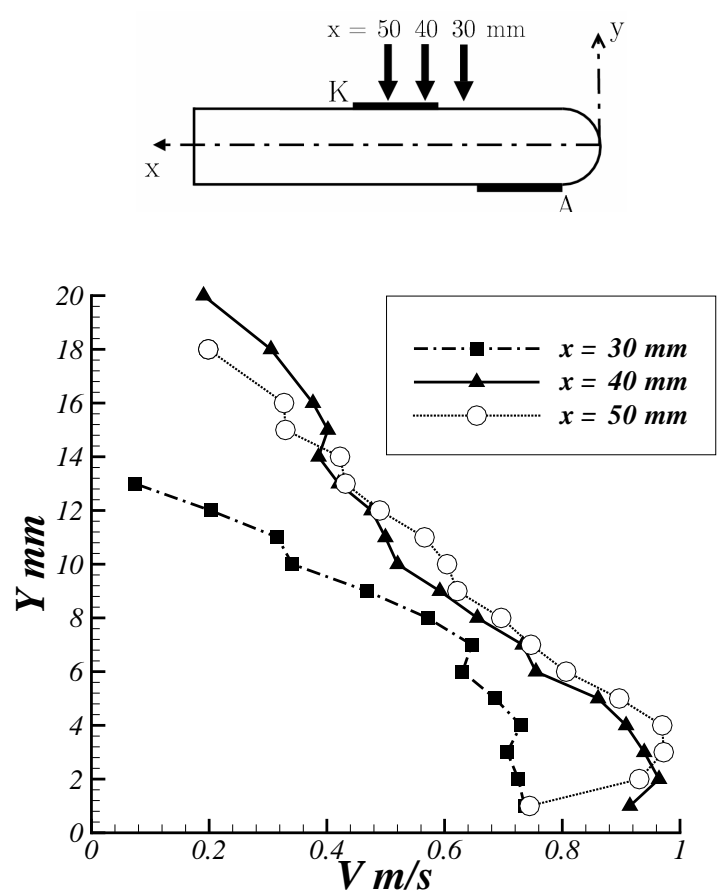

Fig. 7 Ionic wind time-averaged velocity profiles at different positions with a discharge current of $1.2 \mathrm{~mA} / \mathrm{m}$

were measured with the pressure sensing probe (figure 7). The openning diameter of the pressure sensing probe was considered for the Y-axis origin. The voltage of the positive DC surface corona discharge was $+44 \mathrm{kV}$ and the current was $1.2 \mathrm{~mA} / \mathrm{m}$. The maximum velocity was about $1 \mathrm{~m} / \mathrm{s}$ in this configuration. Larger velocity fields were visualized with the PIV system.

However, to avoid disturbances of the camera CCD and the TSI synchronizer system when the electric current was too high (risk of electric arcs), the discharge current was limited to $0.8 \mathrm{~mA} / \mathrm{m}$. Figure 8 represents the complete time averaged velocity field along the flat plate with streamlines. The black silhouette corresponds to the test flat plate.

Velocity profiles cannot be plotted with the pressure sensing probe in the zone between the leading edge and $25 \mathrm{~mm}$ downstream because of great fluctuations in pressure measurements. This was due to a recirculation zone, visualized on figure 8 by PIV measurements. Thus the flow is turbulent in this area, which explains why measurements were only possible downstream there.

Moreover velocity fields were measured with different discharge currents: $0.4 \mathrm{~mA} / \mathrm{m}, 0.6 \mathrm{~mA} / \mathrm{m}$ and $1.2 \mathrm{~mA} / \mathrm{m}$. The comparison of these different velocity fields is presented on figure 9 . In spite of low currents and although the discharge was invisible to the naked eye (for discharge currents of $0.4 \mathrm{~mA} / \mathrm{m}$ and $0.6 \mathrm{~mA} / \mathrm{m}$ ), a flow was set up around the plate. 


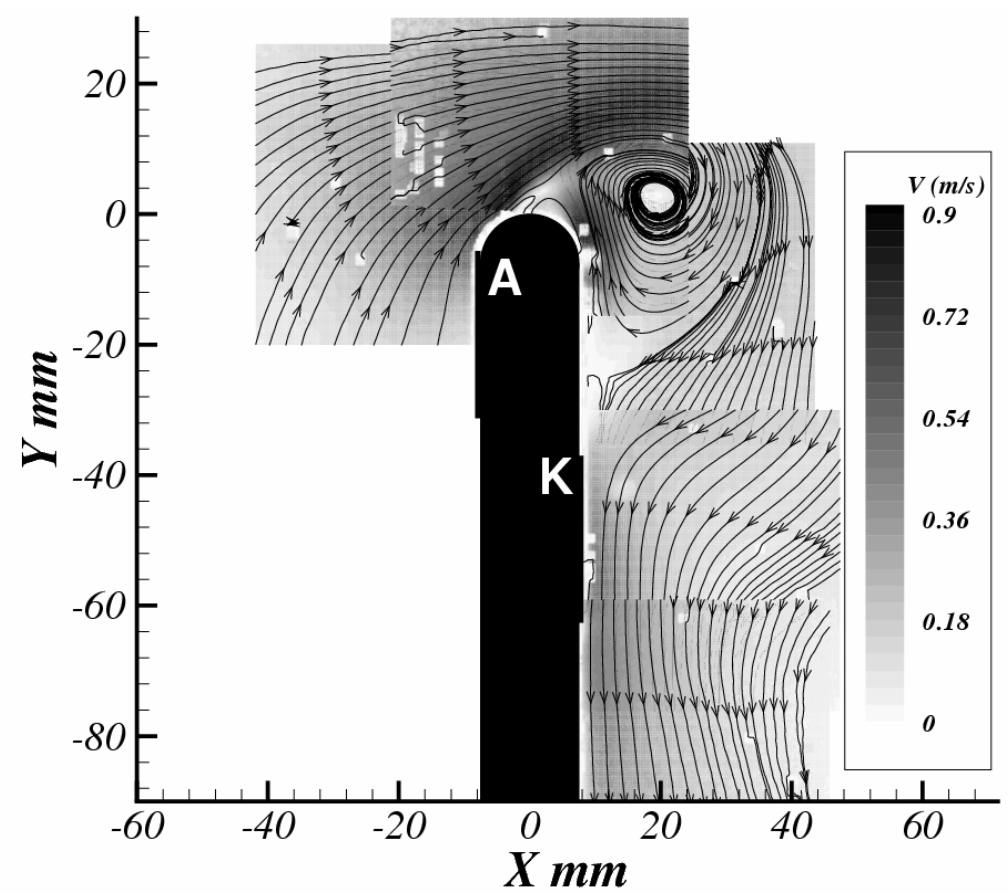

Fig. 8 Complete time averaged velocity with streamlines field around the flat plate with a DC surface corona discharge following the leading edge geometry with a discharge current of $0.8 \mathrm{~mA} / \mathrm{m}$
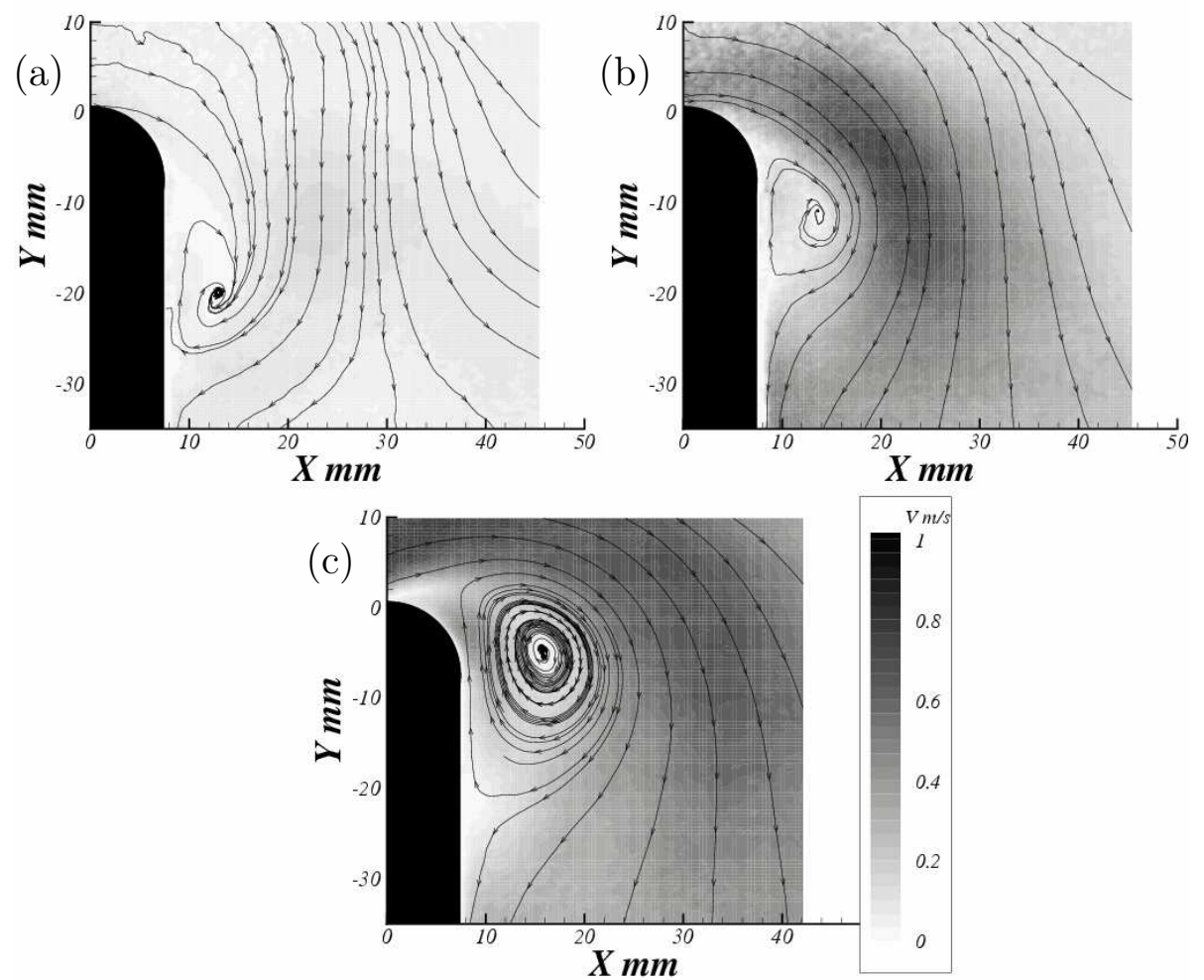

Fig. 9 Time averaged velocity fields with streamlines around the leading edge of the flat plate with a discharge current of (a) $0.4 \mathrm{~mA} / \mathrm{m}$, (b) $0.6 \mathrm{~mA} / \mathrm{m}$ and (c) $1.2 \mathrm{~mA} / \mathrm{m}$ (with the same velocity scale) 


\subsection{Discussion}

The movement of ions, very close to the flat plate wall, generates a movement of molecules around the plate by transfer of momentum. Depending on the discharge current, the Reynolds number of the induced flow, calculated with the maximum velocity of the ionic wind and the circular leading edge diameter for the characteristic length, is between 500 and 1000 . The maximum of velocity value is about $1 \mathrm{~m} / \mathrm{s}$. This value is smaller than those obtained by Moreau et al (2006) and Leger (2003) where velocities up to 3.5 $\mathrm{m} / \mathrm{s}$ were reached. However, our configuration was geometrically different compared with the one used by these authors, we did not use the same kind of electrodes (they used copper wires) and the dielectric material was also different (they used a plate in PMMA). Therefore velocities of the induced flow cannot be compared. The induced flow topology can be observed on figure 8, where the following features can be noted:

- A flow separation at the anode. This is the area with the maximum mean velocity (about $1 \mathrm{~m} / \mathrm{s}$ ).

- A recirculation zone on the top of the flat plate, at the leading edge level.

- A flow re-attachment and an acceleration at the cathode (about $0.6 \mathrm{~m} / \mathrm{s}$ ). Then the flow is parallel to the plate surface downstream the cathode.

Probably an important part of the energy is lost in the recirculation zone and explains why the induced flow velocity is quite low. The reciculation zone was located at various places depending on the discharge current, as shown in figure 9. The higher was the discharge current, the closer was the recirculation zone to the flat plate leading edge. Moreover the mean velocity value increased with the discharge current. The maximum velocity of the flow induced by the electric discharge was about $0.2 \mathrm{~m} / \mathrm{s}$ for a discharge current of $0.4 \mathrm{~mA} / \mathrm{m}$, about $0.7 \mathrm{~m} / \mathrm{s}$ for $0.6 \mathrm{~mA} / \mathrm{m}$ and $1 \mathrm{~m} / \mathrm{s}$ for $1.2 \mathrm{~mA} / \mathrm{m}$. Indeed with a stronger electric field, more particles are ionized and move between electrodes in the vicinity of the surface, and more the acceleration of ions is important. Thus more neutral molecules of gas are involved by this ion movement, with a higher velocity. The energy brought into play for the movement of gas therefore increases with the discharge current until the discharge spark regime (characterized by electric arcs).

The shape, the location and the direction of rotation of this recirculation zone are particular and give interesting informations for numerical simulations. If we consider the electric field between the two electrodes, calculated with the Laplace equation, and if we apply an electric force to the flow in the vicinity of the obstacle, we obtain the type of recirculation showed in figure 10a. To describe the influence 

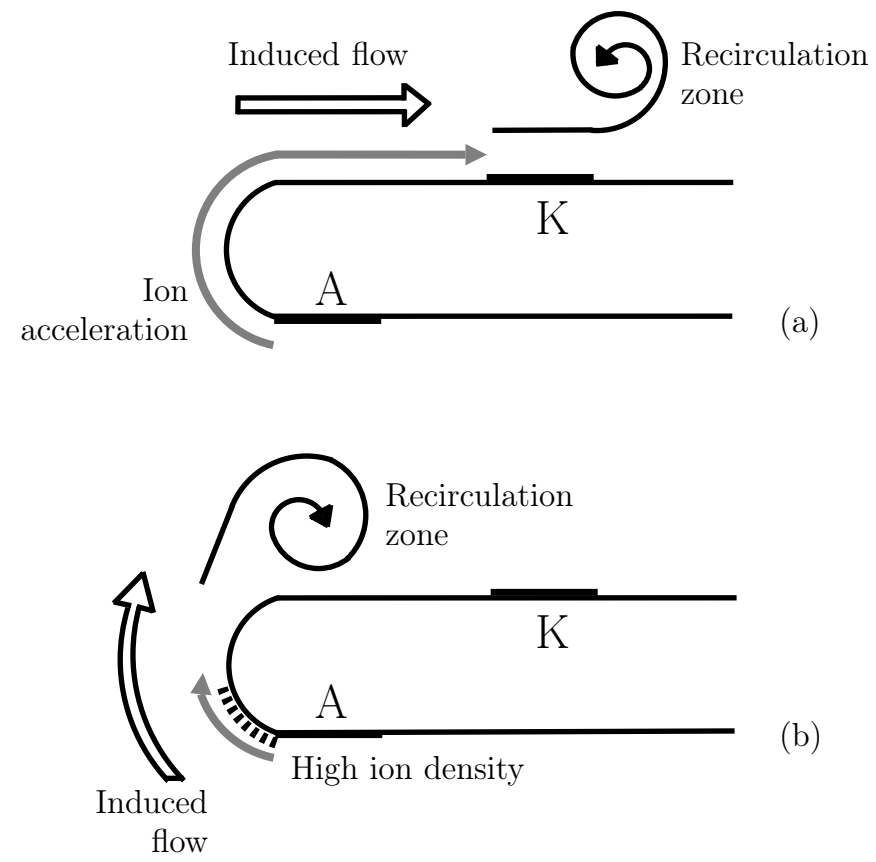

Fig. 10 Schematic figure of the induced flow model (a) with the hypothesis of a uniform electric field and (b) with the hypothesis on a non-uniform electric field

of the discharge on airflow, this approach can give interesting results for other electrodes configurations (Louste et al. (2004), Mateo-Velez et al. (2004)). However, in our case, the experimental results prove that this theoretical approach is not applicable. To improve numerical modeling, it is necessary to take into account a more precise model of the electrical discharge allowing the knowledge of the charge space zone and the right shape of the electric field. Moreover we show that the induced flow field directly depends on the electrostatic characteristics of the plasma.

Consequently, considering our physical model, the corona discharge established in our configuration of two electrodes placed on both sides of the circular leading edge of a flat plate is different from the linear configurations studied by Moreau et al. (2006), Léger (2003), Sosa et al. (2006). The distribution of charged particles is strongly inhomogeneous and the electric field is clearly modified. The applied forces on the neutral gas are not uniform and the velocity field is therefore strongly affected. Moreover the influence of the material used for the plate on the corona discharge could be more important in our configuration. Indeed the material may act as a dielectric barrier and prevents from electric arcs, and may more actively act on charge movement and ionization. 


\section{Effect of the DC corona discharge on the airflow}

Experiments with external subsonic airflow on the flat plate and a wing profile NACA 0015 were performed in the wind tunnel presented in section 2. The effects of the high voltage discharge were observed with the PIV system, for different angles of attack $\alpha$ and different inlet velocities $V$.

To characterize the effect of the electric discharge on an airflow, Leonard et al. (1983) and Davidson and Shaughnessy (1986) proposed a non-dimensional electrohydrodynamic number $N_{E H D}$ which is a measure of the ratio of the electric body force to the inertial force:

$$
N_{E H D}=\frac{i}{l \mu \rho V^{2}}
$$

where $i$ is the discharge current $(\mathrm{A}), l$ is the electrode length $(\mathrm{m}), \mu$ is the ion mobility $\left(\mathrm{m}^{2} /(\mathrm{Vs})\right), \rho$ is the fluid density $\left(\mathrm{kg} / \mathrm{m}^{3}\right)$ and $V$ is the flow velocity $(\mathrm{m} / \mathrm{s})$. In our case, $\rho, l$ and $\mu$ are, respectively, equal to $1.2 \mathrm{~kg} / \mathrm{m}^{3}, 0.17 \mathrm{~m}$ and $10^{-4} \mathrm{~m}^{2} /(\mathrm{Vs})$.

This EHD number was first used by Leger (2003) in airflow control applications. For current electrostatic precipitators, the values of $N_{E H D}$ are between 1 and 2.4 (Soldati and Banerjee (1998)).

Another mean to characterize the EHD actuator effect is the non-dimensional coefficient $C_{W}$, defined by Sosa et al. (2004), which is an expression of the power added to the flow by the electric discharge:

$$
C_{W}=\frac{W}{l} \frac{1}{\frac{1}{2} \rho V^{3} b} \frac{d}{c}
$$

where $W$ is the electric power of the discharge $(\mathrm{W}), \rho$ is the air density $\left(\mathrm{kg} \cdot \mathrm{m}^{-3}\right), b$ is the airfoil thickness, $d$ is the inter-electrode space $(\mathrm{m})$ and $c$ is the airfoil chord $(\mathrm{m})$.

To characterize the level of separation of the flow around the plate or the airfoil, the height $h^{+}$is defined as the the distance from the surface for a null velocity in the wake (by plotting the velocity profiles perpendiculary to the surface at a given position). For example, in velocity profiles plotted in figure 13, when the flow is detached (case without the electric discharge), it presents a recirculating region with a negative velocity and then a positive one, then $h^{+}=12$ in this case. Therefore the parameter $h^{+}$is the height where the velocity sign changes. We also define $h_{E H D}^{+}$which is the same parameter when the electrohydrodynamic actuator is activated. 

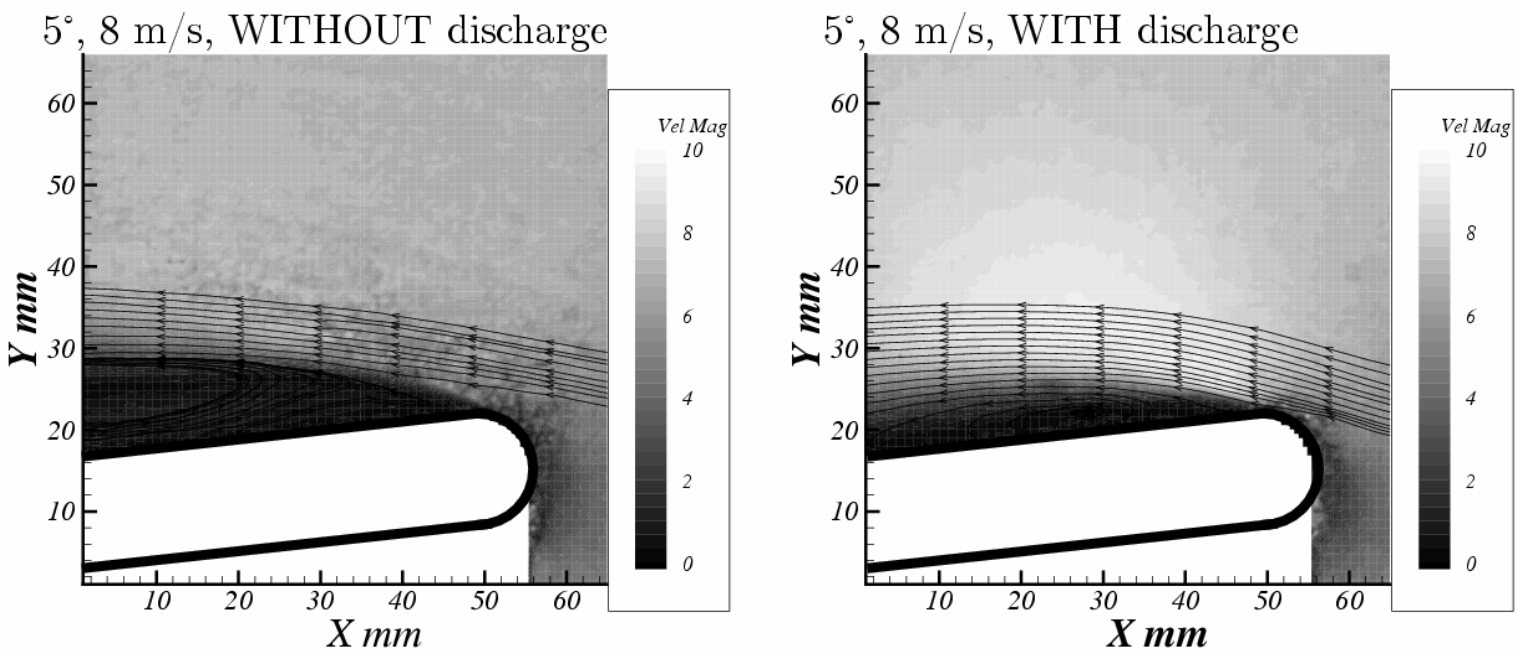

Fig. 11 Comparison of time averaged velocity with streamlines fields with and without high voltage discharge (current of $0.8 \mathrm{~mA} / \mathrm{m}$ ) around the leading edge of the flat plate in the wind tunnel, for an angle of attack of $5^{\circ}$, for $8 \mathrm{~m} / \mathrm{s}$

\subsection{Flow control on a flat plate}

The flat plate with electrodes studied in section 3 (figure 1a) was placed in the subsonic wind tunnel. The current discharge was $0.8 \mathrm{~mA} / \mathrm{m}$. Inlet velocities between $4 \mathrm{~m} / \mathrm{s}$ (with a Reynolds number $R e=53$ 000 and an electrohydrodynamic number $\left.N_{E H D}=0.42\right)$ and $14 \mathrm{~m} / \mathrm{s}\left(R e=187000\right.$ and $\left.N_{E H D}=0.03\right)$ were studied. Velocity fields with flow streamlines were performed with the PIV system. The results are presented in the table 1 with the effects of the discharge on the flow. Parameters $h^{+}$and $h_{E H D}^{+}$were determined $40 \mathrm{~mm}$ downstream the leading edge.

For example, velocity fields with and without the electric discharge, for an angle of attack of $5^{\circ}$ at $8 \mathrm{~m} / \mathrm{s}(R e=107000)$, are presented in figure 11. In the absence of the electric discharge, the flow was completely detached from the flat plate in this case. When the corona discharge was applied, the detachment was significantly reduced for angles of attack up to $5^{\circ}$ and velocities up to $14 \mathrm{~m} / \mathrm{s}$. As this EHD actuator was efficient for modifying completely detached flow on a basic obstacle, we used it on a wing profile.

4.2 Flow control on a wing profile NACA 0015

The DC surface corona discharge was applied on the leading edge of a NACA 0015 airfoil (figure 1b) placed in the wind tunnel. The current discharge was $0.8 \mathrm{~mA} / \mathrm{m}$. Flow velocities between $5 \mathrm{~m} / \mathrm{s}(R e=$ 67000 and $\left.N_{E H D}=0.27\right)$ and $25 \mathrm{~m} / \mathrm{s}\left(R e=333000\right.$ and $\left.N_{E H D}=0.011\right)$ were studied, for angles of 
Table 1 Experimental configurations and effects of the electrohydrodynamic (EHD) actuator on the flow around the flat plate, with $h^{+}$determined $40 \mathrm{~mm}$ downstream the leading edge without the corona discharge and $h_{E H D}^{+}$ with the corona discharge applied

\begin{tabular}{|c|c|c|c|c|c|}
\hline$\alpha$ & $R e\left(10^{3}\right)$ & $N_{E H D}$ & $C_{W}$ & Flow without EHD actuator & Flow with EHD actuator \\
\hline \hline $2.5^{\circ}$ & 53 & 0.42 & 27.5 & Fully separated & $\begin{array}{c}\text { Bubble on the leading edge } \\
\text { and reattachment } \\
h_{E H D}^{+}=2.3 \mathrm{~mm}\end{array}$ \\
\hline $2.5^{\circ}$ & 107 & 0.10 & 3.45 & $\begin{array}{c}\text { Bubble on leading edge } \\
h^{+}=3.2 \mathrm{~mm}\end{array}$ & $\begin{array}{c}\text { Bubble reduced and flow attached } \\
h_{E H D}^{+}=2.8 \mathrm{~mm}\end{array}$ \\
\hline $2.5^{\circ}$ & 187 & 0.03 & 0.64 & $\begin{array}{c}\text { Bubble on leading edge } \\
h^{+}=2.7 \mathrm{~mm}\end{array}$ & $\begin{array}{c}\text { Slight bubble practically disappeared } \\
h_{E H D}^{+}=0.7 \mathrm{~mm}\end{array}$ \\
\hline \hline $5^{\circ}$ & 53 & 0.42 & 27.5 & $\begin{array}{c}\text { Fully separated } \\
h^{+}=5.7 \mathrm{~mm}\end{array}$ & $\begin{array}{c}\text { Bubble on the leading edge } \\
\text { and reattachment } \\
h_{E H D}^{+}=1.1 \mathrm{~mm}\end{array}$ \\
\hline $5^{\circ}$ & 107 & 0.10 & 3.45 & $\begin{array}{c}\text { Fully separated } \\
h^{+}=6.7 \mathrm{~mm}\end{array}$ & $\begin{array}{c}\text { Detachment reduced } \\
h_{E H D}^{+}=2.3 \mathrm{~mm}\end{array}$ \\
\hline $5^{\circ}$ & 187 & 0.03 & 0.64 & $\begin{array}{c}\text { Fully separated } \\
h^{+}=6.1 \mathrm{~mm}\end{array}$ & $\begin{array}{c}\text { Detachment reduced } \\
h_{E H D}^{+}=3.5 \mathrm{~mm}\end{array}$ \\
\hline \hline $7.5^{\circ}$ & 53 & 0.42 & 27.5 & $\begin{array}{c}\text { Fully separated } \\
h^{+}=9.9 \mathrm{~mm}\end{array}$ & $\begin{array}{c}\text { Slight reduction of detachment } \\
h_{E H D}^{+}=8.2 \mathrm{~mm}\end{array}$ \\
\hline $7.5^{\circ}$ & 107 & 0.10 & 3.45 & $\begin{array}{c}\text { Fully separated } \\
h^{+}=10.7 \mathrm{~mm}\end{array}$ & $\begin{array}{c}\text { No significant effect } \\
h_{E H D}^{+}=10.3 \mathrm{~mm}\end{array}$ \\
\hline
\end{tabular}

attack between $12.5^{\circ}$ and $17.5^{\circ}$. The results for all configurations are presented in table 2. Parameters $h^{+}$and $h_{E H D}^{+}$were determined $60 \mathrm{~mm}$ downstream the leading edge. Velocity fields and flow streamlines for $20 \mathrm{~m} / \mathrm{s}$ and $15^{\circ}$ are presented in figure 12 . Velocity profiles were plotted for two inlet velocities $5 \mathrm{~m} / \mathrm{s}$ and $20 \mathrm{~m} / \mathrm{s}$, for $15^{\circ}, 60 \mathrm{~mm}$ downstream the leading edge (figure 13).

\subsection{Discussion}

The use of the high voltage discharge studied in section 3 permitted to modify the airflow on a flat plate for angles up to $7.5^{\circ}$ (at $R e=53000$ ) and for Reynolds numbers up to 187000 (at $2.5^{\circ}$ ). Effects on the flow were measured on the NACA 0015 wing profile for angles up to $17.5^{\circ}$ and for Reynolds numbers up to 267 000. In the case of experiments on the airfoil, we were limited by a Reynolds effect at high Reynolds numbers for $12.5^{\circ}$ and $15^{\circ}$ in order to study the effect of the electric discharge on the flow separation. For high angles of attack and low Reynolds numbers, the boundary layer becomes thicker and is easily separable, whereas for higher Reynolds numbers we have the opposite effect. Therefore in this case, the only modification of the flow with the discharge is a slight increase of mean velocity in the vicinity of the surface airfoil.

Fully separated flows on a wing profile were modified for higher Reynolds numbers than those studied by Roth (2004) with the OAUGDP ${ }^{\mathrm{TM}}$ (up to $\left.R e=25000\right)$, and by Léger et al. (2001) with a DC corona 
Table 2 Experimental configurations and effects of the electrohydrodynamic (EHD) actuator on the flow around the NACA 0015, with $h^{+}$determined $60 \mathrm{~mm}$ downstream the leading edge without the corona discharge and $h_{E H D}^{+}$with the corona discharge applied

\begin{tabular}{|c|c|c|c|c|c|}
\hline$\alpha$ & $\operatorname{Re}\left(10^{3}\right)$ & $N_{E H D}$ & $C_{W}$ & Flow without EHD actuator & Flow with EHD actuator \\
\hline $12.5^{\circ}$ & 67 & 0.27 & 7.06 & $\begin{array}{l}\text { Fully separated } \\
h^{+}=11.1 \mathrm{~mm}\end{array}$ & $\begin{array}{c}\text { Reattached } \\
h_{E H D}^{+}=0 \mathrm{~mm}\end{array}$ \\
\hline $12.5^{\circ}$ & 133 & 0.07 & 0.88 & $\begin{array}{l}\text { Fully attached (Reynolds effect) } \\
\qquad h^{+}=0 \mathrm{~mm}\end{array}$ & $\begin{array}{c}\text { Slight flow acceleration } \\
\text { in the surface vicinity } \\
h_{E H D}^{+}=0 \mathrm{~mm}\end{array}$ \\
\hline $12.5^{\circ}$ & 200 & 0.03 & 0.26 & $\begin{array}{l}\text { Fully attached (Reynolds effect) } \\
\qquad h^{+}=0 \mathrm{~mm}\end{array}$ & $\begin{array}{c}\text { No effect } \\
h_{E H D}^{+}=0 \mathrm{~mm}\end{array}$ \\
\hline $15^{\circ}$ & 67 & 0.27 & 7.06 & $\begin{array}{l}\text { Fully separated } \\
h^{+}=12.2 \mathrm{~mm}\end{array}$ & $\begin{array}{c}\text { Reattached } \\
h_{E H D}^{+}=0 \mathrm{~mm}\end{array}$ \\
\hline $15^{\circ}$ & 133 & 0.07 & 0.88 & $\begin{array}{c}\text { Fully separated } \\
h^{+}=13.0 \mathrm{~mm}\end{array}$ & $\begin{array}{c}\text { Reattached } \\
h_{E H D}^{+}=0 \mathrm{~mm}\end{array}$ \\
\hline $15^{\circ}$ & 200 & 0.03 & 0.26 & $\begin{array}{c}\text { Fully separated } \\
h^{+}=13.9 \mathrm{~mm}\end{array}$ & $\begin{array}{c}\text { Reattached } \\
h_{E H D}^{+}=0 \mathrm{~mm}\end{array}$ \\
\hline $15^{\circ}$ & 267 & 0.02 & 0.11 & $\begin{array}{c}\text { Fully separated } \\
h^{+}=13.6 \mathrm{~mm}\end{array}$ & $\begin{array}{c}\text { Reattached } \\
h_{E H D}^{+}=0 \mathrm{~mm}\end{array}$ \\
\hline $15^{\circ}$ & 333 & 0.01 & 0.05 & $\begin{array}{l}\text { Fully attached (Reynolds effect) } \\
\qquad h^{+}=0 \mathrm{~mm} \\
\end{array}$ & $\begin{array}{c}\text { Slight flow acceleration } \\
\text { in the surface vicinity } \\
h_{E H D}^{+}=0 \mathrm{~mm}\end{array}$ \\
\hline $17.5^{\circ}$ & $\overline{67}$ & $\overline{0.27}$ & 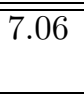 & $\begin{array}{l}\text { Fully separated } \\
h^{+}=22.2 \mathrm{~mm}\end{array}$ & $\begin{array}{l}\text { Slight reduction of detachment } \\
h_{E H D}^{+}=20.2 \mathrm{~mm}\end{array}$ \\
\hline $17.5^{\circ}$ & 133 & 0.07 & 0.88 & $\begin{array}{c}\text { Fully separated } \\
h^{+}=21.0 \mathrm{~mm}\end{array}$ & $\begin{array}{c}\text { Detachment reduced } \\
h_{E H D}^{+}=17.5 \mathrm{~mm}\end{array}$ \\
\hline $17.5^{\circ}$ & 200 & 0.03 & 0.26 & $\begin{array}{c}\text { Fully separated } \\
h^{+}=22.3 \mathrm{~mm}\end{array}$ & $\begin{array}{c}\text { Detachment reduced } \\
h_{E H D}^{+}=17.3 \mathrm{~mm}\end{array}$ \\
\hline $17.5^{\circ}$ & 267 & 0.02 & 0.11 & $\begin{array}{l}\text { Fully separated } \\
h^{+}=21.4 \mathrm{~mm}\end{array}$ & $\begin{array}{c}\text { Detachment reduced } \\
h_{E H D}^{+}=16.8 \mathrm{~mm}\end{array}$ \\
\hline
\end{tabular}

discharge (up to $R e=68$ 600). However our Reynolds values were lower than those reported by Corke et al. (2004) $(R e=307$ 000), Post and Corke (2003) $(R e=460$ 000) and Opaits et al. $(2005)(R e=$ 450 000). Moreover we used an electric discharge more powerful than the one used by Sosa et al. (the parameter $C_{W}$ is higher in our experiments) whereas they modified subsonic airflows for higher Reynolds number (up to 333 333). Thus continuous discharges seem to be less efficient compared to pulsed and alternative discharges for modifying subsonic flows.

Figures 11, 12 and 13 indicate that the EHD actuator enables to reduce the flow separation and can make it disappear in some cases. The actuator efficiency depends on the flow regime around the flat plate and the airfoil. Values of the parameter $h^{+}$indicate the importance of the detachment or the bubble. The surface corona discharge enables to make disappear small bubbles on the leading edge (for the flat plate for $2.5^{\circ}$ and $R e=107000$ ) and only to reduce the bigger bubbles (for the flat plate for $2.5^{\circ}$ and $R e=187$ 000). Moderate fully separated flows were fully re-attached by action of the electric discharge (for the flat plate for $2.5^{\circ}$ and $5^{\circ}$ at $R e=53000$, for the airfoil for $15^{\circ}$ at $R e$ beetween 67000 and 267 

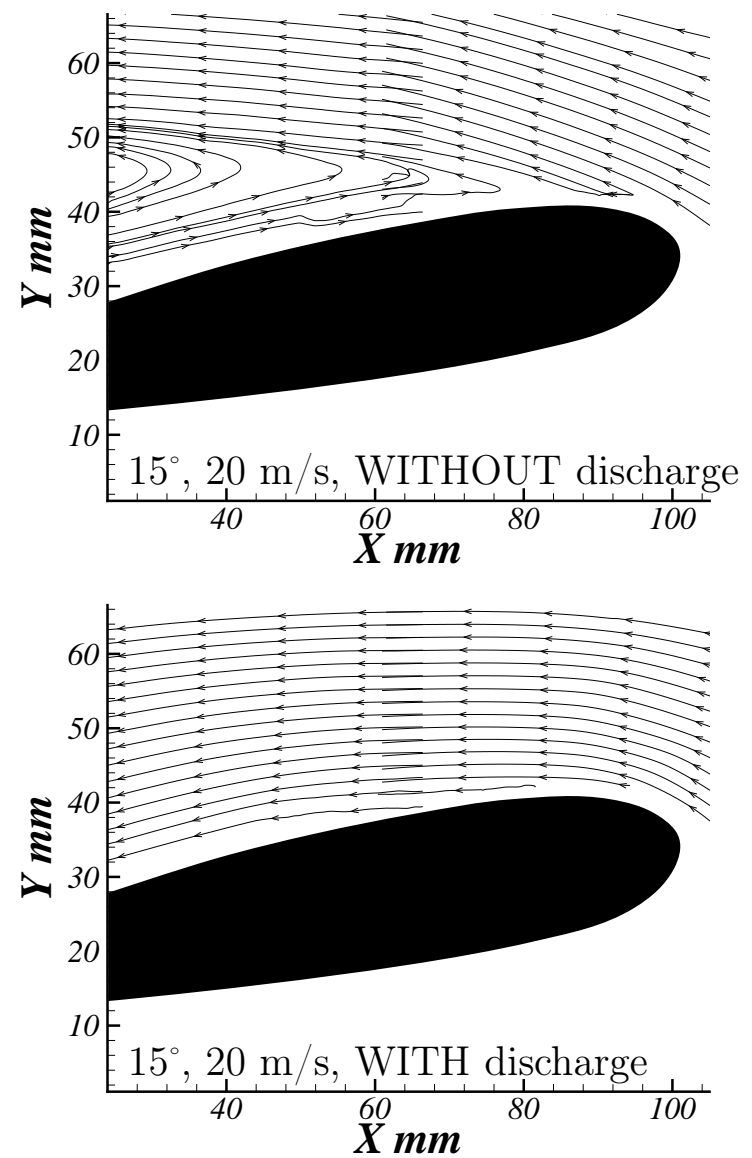

Fig. 12 Comparison of velocity streamlines with and without high voltage discharge (current of $0.8 \mathrm{~mA} / \mathrm{m}$ ) around the leading edge of the NACA 0015 wing profile in the wind tunnel, for an angle of attack of $15^{\circ}$, for 20 $\mathrm{m} / \mathrm{s}$
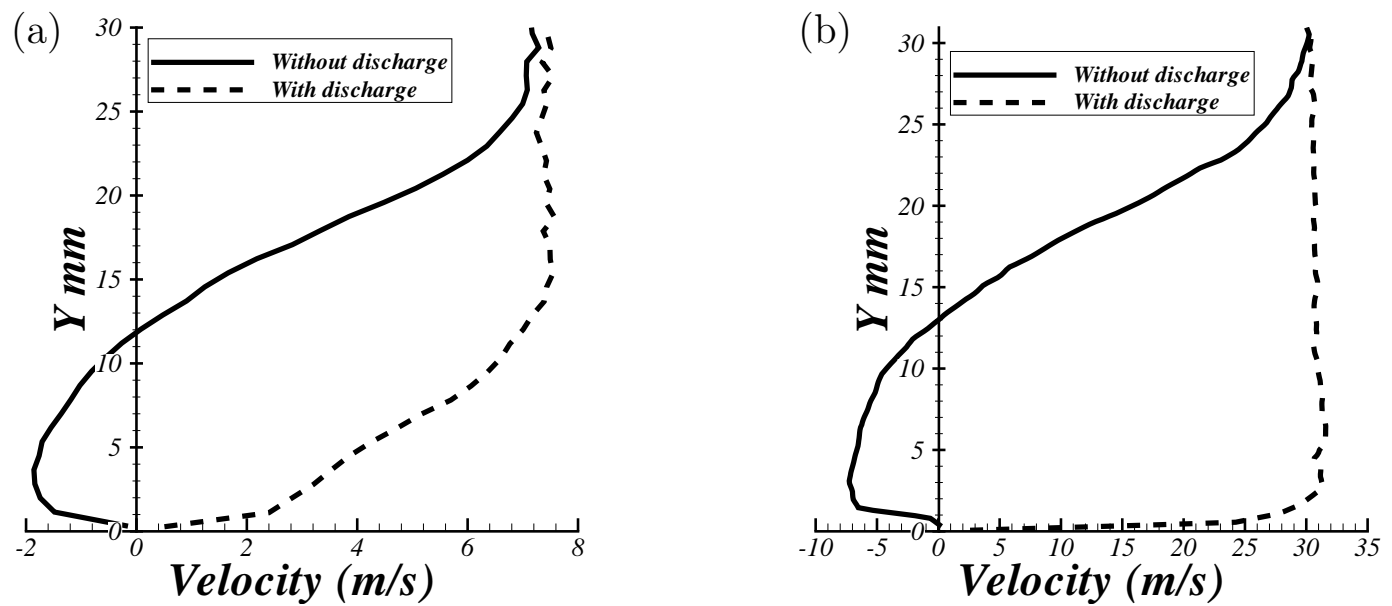

Fig. 13 Velocity profiles with and without high voltage discharge (current of $0.8 \mathrm{~mA} / \mathrm{m}$ ) for an angle of attack of $15^{\circ}$, at $60 \mathrm{~mm}$ downstream the leading edge, for a flow velocity in the wind tunnel of (a) $5 \mathrm{~m} / \mathrm{s}$ and (b) $20 \mathrm{~m} / \mathrm{s}$

000, figure 12) but strongly fully separated flows were only reduced (for the flat plate, for example for $5^{\circ}$ at $R e=107$ 000, figure 11). Without the EHD actuator, the boundary layer is laminar on the leading edge, which is quite unstable and is detached (with a recirculating region, figure 13). By action of the electric discharge, an induced flow is added to the boundary layer in the vicinity of the surface and leads 
to its transition to a turbulent boundary layer. Therefore the boundary layer is thiner, the flow is nearer to the surface and cannot separate. This effect on the boundary layer by the electric discharge (and the induced flow) becomes more marked by a Reynolds effect: the more the Reynolds number increases, the more the re-attached boundary layer is turbulent and near to the surface. Indeed, on the velocity profiles plotted $60 \mathrm{~mm}$ downstream the NACA 0015 leading edge at $15^{\circ}$ in figure 13 , the re-attached boundary layer at $5 \mathrm{~m} / \mathrm{s}$ was near to the surface on $1.2 \mathrm{~mm}$, but the boundary layer global thickness was $12 \mathrm{~mm}$. For higher Reynolds number, at $20 \mathrm{~m} / \mathrm{s}$, the re-attached boundary layer was turbulent with a thickness of $2 \mathrm{~mm}$. So the EHD actuator causes the boundary layer transition on the leading edge and the flow is then attached, the boundary layer is increasingly turbulent with the Reynolds number and the flow is strongly attached. Therefore high Reynolds numbers combined with the effect of the electric discharge were helpful for reducing strongly separated flows, for example in the case of $17.5^{\circ}$ and $R e=267000$, whereas the flow was more detached for lower Reynolds numbers.

In our experiments, bubbles and detachment of the flow were made on the leading edge, where were placed electrodes for establishing the DC surface corona discharge. We performed several experiments with electrodes placed at the airfoil trailing edge for these high angles of attack and these Reynolds numbers on the NACA 0015 wing profile, but the discharge had no effect on the airflow. However Sosa and Artana (2006) modified the detached flow on the trailing edge at low Reynolds numbers (up to 50 000) with a corona discharge applied at the trailing edge. Corke et al. (2004) uniformly increased the lift coefficient with a pulsed discharge acting on a NACA 0015 trailing edge, for low angles of attack (in the lift coefficient versus $\alpha$ linear region). The electric discharge is efficient when it is placed in the flow separation area on the wing profile (here, for high angles of attack, at the leading edge). This result confirms the experiments performed by Jolibois et al. (2006). Thus not only the discharge current and the induced flow velocity are important parameters, but the discharge location on the obstacle is also crucial for flow control.

\section{Conclusion}

The present experimental study of a DC corona surface discharge contouring the leading edge geometry of a flat plate and a NACA 0015 wing profile was performed. With pressure sensing probe measurements and PIV visualizations, the ionic wind induced by the discharge presented a detachment, a recirculation zone and a re-attachment. Variations in the discharge current modified the shape of the velocity and 
values of the mean velocity. From these results, a physical induced flow model is presented and shows that the electric field and the ion density may be strongly inhomogeneous in the interelectrode space with our configuration.

Although the mean velocity value of the flow induced by this electric discharge was about $1 \mathrm{~m} / \mathrm{s}$, the detached flows on a flat plate and the NACA 0015 wing profile were significantly modified for Reynolds numbers up to 267000 and for angles of attack up to $17.5^{\circ}$. From these experiments, we show that the EHD actuator with a DC surface corona discharge enables to reduce the detached flow on an airfoil for high angles of attack and higher Reynolds number than previously reported with DC surface corona discharges. However continuous discharge efficiency seems to be less important than AC and pulsed discharges in literature. We showed that the efficiency of the electric discharge depends on the flow regime and the degree of detachment of the flow. Moderate fully separated flows were fully re-attached whereas strongly separated flows were only reduced. The flow induced by the high voltage discharge adds velocity to the boundary layer in the vicinity of the surface, makes it turbulent and prevents the flow from separating. Effects of the EHD actuator combined with a Reynolds effect enable to significantly reduce highly detached flows. Moreover this study demonstrates that the discharge location on the obstacle is an important parameter to control the flow.

Generally, the electrohydrodynamic number $N_{E H D}$ is not a very interesting parameter to characterize the effect of the discharge on the flow when the angle of attack varies. For example, for the same $N_{E H D}$ of 0.42 , the flow regime was different for $2.5^{\circ}$ and $7.5^{\circ}$ for the flat plate, and the EHD actuator efficiency was not the same. The whole of the results presented in the tables is to show the tendencies and to constitute a whole of results which can be compared with results of other experimental studies or simulations.

In future studies, the EHD actuator will be tested for higher Reynolds number, with higher airfoil dimensions and higher flow velocities. Moreover further experiments are needed to gain better understanding of interactions between the ionic wind induced by the electric discharge and the boundary layer, and thus the physical mechanisms by which the detached flow on the airfoil can be re-attached by the EHD actuator.

Acknowledgements The authors would like to thank Stéphane Loyer (LME) and Erwan Le Menn (GREMI) for their assistance in setting up these experiments and fixing numerous problems encountered along the way. We would also like to thank Sandrine Aubrun and Régine Weber (LME) for their help during this period. 


\section{References}

1. Anders SG, Sellers WL, Washburn AE, Active flow control activities at NASA Langley, AIAA Paper, 2004-2623 (2004).

2. Artana G, DiPrimio G, Desimone G, Moreau E, Touchard G, Electrohydrodynamic actuators on a subsonic air flow around a circular cylinder, AIAA Paper, 2001-3056 (2001).

3. Artana G, D'Adamo J, Léger L, Moreau E, Touchard G, Flow control with electrohydrodynamic actuators, AIAA Journal, 40 (9), 1773-1779 (2002).

4. Corke TC, He C, Patel MP, Plasma flapts and slats: an application of weakly-ionized plasma actuators, AIAA Paper, 2004-2127 (2004).

5. Corke TC, Post ML, Overview of plasma flow control: concepts, optimization and applications, AIAA Paper, 2005-0563 (2005).

6. Corke TC, Merts B, Patel MP, Plasma flow control optimized airfoil, AIAA Paper 2006-1208 (2006).

7. Davidson JH, Shaughnessy EJ, Turbulence generation by electric body forces, Exp Fluids, 4, 17-26 (1986).

8. El-Khabiry S, Colver G, Drag reduction by DC corona discharge along an electrically conductive flat plate for small Reynolds number flows, Phys Fluids, 9 (3), 587-599 (1997).

9. Hyun KT, Chun CH, The wake flow control behind a circular cylinder using ion wind, Exp Fluids, 35, 541-552 (2003).

10. Jedrusik M, Galewski JB, Swierczok AJ, Effect of the particle diameter and corona electrode geometry of the particle migration velocity in electrostatic precipitators, J Electrostat, 51-52, 245-251 (2001).

11. Jolibois J, Forte M, Moreau E, Separation control along a NACA0015 airfoil using a dielectric barrier discharge actuator, IUTAM Symposium on flow control and mems, London (UK), September 2006, in press.

12. Kalman H, Sher E, Enhancement of heat transfer by means of a corona wind created by a wire electrode and confined wings assembly, Applied Thermal Engineering, 21, 265-282 (2001)

13. Kuroda Y, Kawada Y, Takahashi T, Ehara Y, Ito T, Zukeran A, Kono Y, Yasumoto K, Effect of electrode shape on discharge current and performance with barrier discharge type electrostatic precipitator, J. Electrostat., $57,407-415(2003)$.

14. Labergue A, Léger L, Moreau E, Touchard G, Effect of a plasma actuator on an airflow along an inclined wall: P.I.V. and wall pressure measurements, J Electrostat, 63, 961-967 (2005).

15. Leger L, Moreau E, Artana G, Touchard G, Influence of a DC corona discharge on the airflow along an inclined flat plate, J Electrostat, 51-52, 300-306 (2001).

16. Leger L, Contrôle actif d'un écoulement d'air par un plasma froid surfacique, PhD Thesis, Université de Poitiers (2003)

17. Leonard GL, Mitchner M, Self SA, An experimental study of the electrohydrodynamic flow in electrostatic precipitators, J Fluid Mech, 127, 123-140 (1983).

18. Louste C, Moreau E, Artana G, Touchard G, Étude de l'action mécanique d'une décharge de surface par mesure PIV et simulation, 4th Conférence SFE, Poitiers, 174-179 (2004). 
19. Mateo-Velez JC, Thivet F, Degond P, Modélisation élémentaire du vent ionique dans une décharge couronne, 4th Conférence SFE, Poitiers, 180-185 (2004).

20. Marco SM, Velkoff HR, Effect of electrostatic fields on free-convection heat transfer from flat plates, American Society of Mechanical Engineers, Paper No 63-HT-9 (1964).

21. Moreau E, Léger L, Touchard G, Effect of a DC surface-corona discharge on a flat plate boundary layer for air flow velocity up to $25 \mathrm{~m} / \mathrm{s}$, J Electrostat, 64, Issues 3-4, 215-225 (2006).

22. Moreau E, Airflow control by non thermal plasma actuators, Journal of Phys. D : Appl Phys, 40, 605-636 (2007).

23. Opaits DF, Roupasov DV, Starikovskaia AY, Zavialov IN, Saddoughi SG, Plasma control of boundary layer using low-temperature non equilibrium plasma of gas discharge, AIAA Paper, 2005-1180 (2005).

24. Post ML, Corke TC, Separation on high angle of attack airfoil using plasma actuators, AIAA Paper, 2003-1024 (2003).

25. Robinson M, Movement of air in the electric wind of a corona discharge, AIEE transactions, 80, 143-150 (1961).

26. Roth JR, Sherman DM, Wilkinson SP, Boundary Layer Flow Control with a One Atmosphere Uniform Glow Discharge Surface Plasma, AIAA Paper 98-0328, 36th Aerospace Sciences Meeting and Exhibit, Reno, NV, January 12-15 (1998).

27. Roth JR, Sherman DM, Wilkinson SP, Electrohydrodynamic flow control with a glow-discharge surface plasma, AIAA Journal, 38 (7), 1166-1172 (2000).

28. Roth JR, Sin H, Madhan RCM, Wilkinson SP, Flow re-attachement and acceleration by paraelectric and peristaltic electrohydrodynamic (EHD) effects, AIAA Paper, 2004-0845 (2004).

29. Shcherbakov YV, Isanov NS, Baryshev ND, Frolovskij VS, Syssoev VS, Drag reduction by AC streamer corona discharges along a wing-like profile plate, AIAA Paper, 2000-2670 (2000).

30. Soldati A, Banerjee S, Turbulence modification by large-scale organized electrohydrodynamic flows, Phys Fluids, 10 (7), 1742-1756 (1998).

31. Sosa R, Moreau E, Touchard G, Artana G, Stall control at high angle of attack with periodically excited EHD actuators, AIAA Paper, 2004-2738 (2004).

32. Sosa R, Artana G, Steady control of laminar separation over airfoils with plasma sheet actuators, J Electrostat, $64(7-9), 604-610$ (2006).

33. Velkoff H, Ketcham J, Effect of an electrostatic field on boundary layer transition, AIAA Journal, 16(7), 1381-1383 (1968).

34. Yamamoto T, Velkoff HR, Electrohydrodynamics in an electrostatic precipitator, J. Fluid Mech., 108, 1-18 (1981). 